\title{
Access to research and Sci-Hub Creating opportunities for campus conversations on open access and ethics
}

$\mathbf{S}$ ci-Hub is a repository that makes illegal access to academic papers possible to anyone. It has generated a spectrum of responses from librarians, publishers, and open access advocates. Some have defended ${ }^{1}$ Sci-Hub and its creator, Alexandra Elbakyan, while others have denounced ${ }^{2}$ the repository. Coverage of Sci-Hub has been extensive. Science published an article ${ }^{3}$ in April 2016 that attempted to answer questions about who uses Sci-Hub, where those users are located, and what they are downloading. American Libraries followed with a primer ${ }^{4}$ on the issue. Perhaps the most useful analysis of Sci-Hub came from Ernesto Priego in his article in The Winnower entitled "Signal, Not Solution: Notes on Why Sci-Hub is Not Opening Access." He holds that Sci-Hub might offer a technological solution to access, but it fails to address complex moral, social, and legal barriers in a sustainable way.

If his claim is true, and publishers, metrics, and reward systems remain largely unchanged, the real value of Sci-Hub to the library community, then, is to use the repository as a case study for asking our faculty and students larger questions about responsibility and sustainable change. Posts and articles about the repository illustrate that it is a topic ripe for conversations about ethics, technology, copyright, and inequality.

In August 2016, Amy Buckland asked the ALA ScholComm listserv 5 to share examples of the Sci-Hub outreach they were doing. She received only one response publicly, ${ }^{6}$ possibly suggesting that librarians have yet to introduce this issue on their campuses. As librarians, we need to recognize that discussing Sci-Hub with our communities can provide an opportunity to promote our vision for the future of scholarly communication while intentionally, collaboratively building a future where Sci-Hub is no longer needed or relevant.

We know that we need community and buy-in to build a more open future. Some have suggested that Sci-Hub's existence illustrates how "relatively little progress" the open access movement has made and that change has been mostly "slow, gradual, and friendly." I would argue that Sci-Hub gives us an opportunity to amend this and not only educate but excite our communities about legal open access. An inherent goal in educating our communities about a guerilla approach to open access is to teach them about other avenues for openness, expose the complexities of our broken systems, and provide an alternative view of what scholarly publishing and researcher workflows could look like.

In September 2016, I facilitated a panel discussion on Sci-Hub, ethics, and the college's honor code. This event provides one model for librarians interested in starting conversations about Sci-Hub on their campuses.

Sarah Crissinger is information literacy librarian at Davidson College, email: sacrissinger@davidson.edu

(C) 2017 Sarah Crissinger 


\section{Campus context: Ethics at Davidson College}

The idea for the Sci-Hub panel stemmed from a faculty member's concern. This faculty member had read about Sci-Hub in Science and wanted to know more about what the library and information technology were doing to restrict students' access to the repository. They were concerned with illegal activity and possible honor code violations on Davidson College's campus. At the same time, they were interested in the library community's response to Sci-Hub. After a rigorous and friendly debate with the faculty member, I realized that Sci-Hub could provide a fruitful case study for starting a deeper discussion and that we could replicate our conversation on a larger scale.

As I brainstormed possibilities, I recognized that institutional context would be important for making a Sci-Hub event successful. An integral part of Davidson College's identity is its honor code. ${ }^{9}$ The honor code creates a community of honor, integrity, and trust that often appeals to prospective students. Every student signs the code, which states that they will not steal. Davidson's commitment to the honor code provided an interesting ethical framework for the event. Is using Sci-Hub stealing? Is stealing ever justified? Are ethics and morality ever complicated by context? If so, how?

In addition to using institutional context, I took advantage of momentum from a previous event. For Open Access Week 2015, the Davidson College Library hosted a panel on open access and information privilege. The panel, which was a collaborative effort among myself, my colleague Cara Evanson, and a faculty member in Biology, explained the current broken scholarly publishing system, introduced open access as a social justice movement, and addressed how access tangibly impacts Davidson students and faculty. The event was sponsored by Davidson's Vann Center for Ethics, as their goal is to help students work through complex ethical dilemmas. I started to consider how a potential Sci-Hub panel could function as a continuation of this discussion while building upon our existing relationship.

Once the framework was created and a partnership with the Vann Ethics Center was solidified, I created a panel that included a tenured faculty member from Environmental Studies, our chief information officer (CIO), and a senior English major.

\section{The event: Ethical dilemmas of Sci- Hub, the honor code, and access to research}

The 90-minute event, entitled "Access to Research, Sci-Hub, and the Honor Code: Ethical Dilemmas," took place September 22, 2016. The event started with a 15-minute introduction to Sci-Hub and open access, which I presented. ${ }^{10}$ The goal of the introduction was to give the audience an overview of Sci-Hub and context for why Sci-Hub exists, and thus included journal costs, background on faculty reward systems, an explanation of the free labor that supports publishing, and information about other guerilla open access tactics. This context enabled me to present Sci-Hub, and Elbakyan, in more nuance. Instead of painting Elbakyan as hero or villain, I tried to illustrate that her actions are complex and that there is disagreement about Sci-Hub within the open access community itself.

After the introduction, I shared a disclaimer. After Gabriel Gardner was criticized by Thomas Allen of the Association of American Publishers for discussing Sci-Hub at the 2016 ALA Annual Conference, ${ }^{11}$ I wanted to be very clear that neither the panelists, the library, nor the college were endorsing SciHub or Elbakyan. I also wanted to inform the audience that the event was not being recorded and that they could speak freely. I concluded the disclaimer with the goal of the event: to use our "humane instincts," which Davidson College claims to develop in its students, ${ }^{12}$ to think critically about the disparity in information access. I argued that if we did not like or want to accept Sci-Hub as an answer to the disparity in information access, we should construct our own answer and take action. 
I transitioned to the audience discussion portion of the event by asking each panelist a directed question to start the conversation. I tailored each panelist's question to their interests and stake in the conversation. The faculty member provided an interesting perspective on tenure and barriers to open access, including author processing charges. Our CIO discussed morality and technology and the possibility of blocking Sci-Hub, specifically. The student panelist was unable to attend at the last minute, but his question was centered on losing access after graduation. In addition to representing the student, faculty, and staff perspective, each panelist offered a unique take on openness.

With a fairly small audience of about 35 faculty members, staff, and students, we had a rich discussion. We discussed how Davidson students might benefit from all research being open. We touched on Napster and how the music industry was forced to redefine itself, which led to a larger conversation about SciHub acting as a similar impetus for change. One audience member even hypothesized that if all libraries came together and withdrew their budgets from vendors and then used that money consortially, they could build something completely new to share and evaluate research. Most interestingly, we discussed how technology impacts our ethical judgements. Many audience members agreed that they would not judge a faculty member who emailed another faculty member or student the full text of one or two articles. Yet, some felt uncomfortable with what Elbakyan was doing. This led us to ask about scale and how technology-enabled "underground" sharing is often seen differently when it is done more efficiently. ${ }^{13}$

\section{Conclusion}

In his recent conference presentation ${ }^{14}$ on the Guerilla Open Access movement, Balazas Bodo reminds us that the "best antidote to piracy is to create conditions in which they are redundant and obsolete." Librarians should continue to ask themselves how their outreach can further this important goal.
One tactic is to use controversial, current events to revive conversations about access and further our goals for both scholarly communication and information literacy. Barbara Fister noted ${ }^{15}$ a significant change from the definition of information literacy used in the Information Literacy Competency Standards for Higher Education to the definition used in the Framework for Information Literacy for Higher Education: there is a greater emphasis on "creating new knowledge" and "participating ethically" in communities. Sci-Hub can provide another venue to work toward answering this call.

Most importantly, I have found that SciHub outreach puts responsibility back on the local community. Thinking about SciHub contextually and locally can transform Sci-Hub from a controversial topic centered on those without access to an institutionally relevant case study that asks all of us to consider our actions and our sharing practices. Moreover, the extra effort to tailor campus conversations to institutional context and vision make these discussions more impactful and relevant.

Our panel on Sci-Hub was only a first step. While discussion at the event was engaged, we need to work toward connecting the panel to institutional action and outcomes, potentially through an open access policy or programming on green open access. Nevertheless, awareness is the first step to action. In order to revolutionize the broken scholarly communication ecosystem we currently operate in, we must first inform and engage our own communities.

\section{Acknowledgments}

The author is grateful to Heidi Johnson and Joe Gutekanst for their feedback on this piece.

\section{Notes}

1. For examples of pieces defending SciHub, see: Mike Taylor, "Thought-Experiment \#2: What Will Happen if Sci-Hub Fails?,"

(continues on page 95) 
but they were together no matter where. Together, they were like rocks in an Inukshuk, counting on each other and supporting each other as a team. No one was left behind.

Happy Valley-Goose Bay was a starting point of my career. To grow better as a librarian, I must experience more. One year later I resigned, and I received a small Inukshuk sculpture from the college as a gift. Every time
I look at this sculpture, it reminds me of a place called Labrador, where Inukshuks show the way. Once there, always in my blood.

\section{Note}

1. Charles A. Cutter, Rules for a Printed Dictionary Catalogue (Washington: Government Printing Office, 1876).

("Access to research and Sci-Hub," continues from page 88)

March 11, 2016, https://svpow.com/2016/03/11 /thought-experiment-2-what-will-happen-if -sci-hub-fails/ and James Heathers, "Why Sci-Hub Will Win," Medium, May 2, 2016, https://medium.com/@jamesheathers/whysci-hub-will-win-595b53aae9fa\#.t5zewr2vy.

2. For examples of pieces denouncing Sci-Hub, see: Angela Cochran, "A Funny Thing Happened on the Way to OA," The Scholarly Kitchen, February 25, 2016, https:// scholarlykitchen.sspnet.org/2016/02/25/a -funny-thing-happened-on-the-way-to-oa/ and Rick Anderson, "Sci-Hub and Academic Identity Theft: An Open Letter to University Faculty Everywhere," The Scholarly Kitchen, May 19, 2016, https://scholarlykitchen. sspnet.org/2016/05/19/sci-hub-and-academic -identity-theft-an-open-letter-to-university -faculty-everywhere/.

3. John Bohannon, "Who's Downloading Pirated Papers? Everyone," Science Magazine, April 2016.

4. Marcus Banks, "Sci-Hub: What It Is and Why It Matters," American Libraries, May 2016.

5. Amy Buckland to ALA ScholComm mailing list, August 23, 2016, http://lists.ala.org /sympa/arc/scholcomm/2016-08/msg00067. html.

6. Rick Anderson to ALA ScholComm mailing list, August 23, 2016 http://lists.ala.org /sympa/arc/scholcomm/2016-08/msg00069.html.

7. Ernesto Priego, "Signal, Not Solution: Notes on Why Sci-Hub is not Opening Access," The Winnower, February 2016.

8. Balazas Bodo, "Pirates in the Library:
An Inquiry into the Guerilla Open Access Movement" (paper presented at the annual workshop on the International Society for the History and Theory of Intellectual Property, Glasgow, United Kingdom, July 6-8, 2016).

9. "Honor Code," Davidson College, https://www.davidson.edu/about/distinctly -davidson/honor-code.

10. Sarah Crissinger, "Access to Research, Sci-Hub, and the Honor Code: Ethical Dilemmas" (panel, Davidson College, Davidson, NC, September 22, 2016), www.slideshare.net/crissinger2010/access-to -research-scihub-and-the-honor-code-ethical -dilemmas-69960557.

11. For more context on this interactions, see: Scott Jaschik, "Supporting Sci-Hub vs. explaining Sci-Hub," Inside Higher Education, August 8, 2016, https://www.insidehighered. com/news/2016/08/08/letter-publishers -group-adds-debate-over-sci-hub-and -librarians-who-study-it.

12. "Statement of Purpose," Davidson College, https://www.davidson.edu/about /statement-of-purpose.

13. James Heathers addresses this idea in more depth in his blog post, "Why Sci-Hub Will Win." He suggests that illegal sharing happens all of the time, through scholarly networks and Twitter. Sci-Hub simply makes it more convenient and efficient.

14. Balazas Bodo, "Pirates in the Library: An Inquiry into the Guerilla Open Access Movement."

15. Inside Higher Education, March 23, 2016, http://ihenow.com/20aE1ng. 